\title{
Characterization of methicillin-susceptible and -resistant staphylococci in the clinical setting: a multicentre study in Nigeria
}

Adebayo Shittu ${ }^{1,2^{*}}$, Omotayo Oyedara ${ }^{1,3}$, Fadekemi Abegunrin ${ }^{1}$, Kenneth Okon ${ }^{4}$, Adeola Raji5 ${ }^{5}$, Samuel Taiwo ${ }^{6}$, Folasade Ogunsola ${ }^{7}$, Kenneth Onyedibe ${ }^{8}$ and Gay Elisha ${ }^{2}$

\begin{abstract}
Background: The staphylococci are implicated in a variety of human infections; however, many clinical microbiology laboratories in Nigeria do not identify staphylococci (in particular coagulase negative staphylococci - CNS) to the species level. Moreover, data from multi-centre assessment on antibiotic resistance and epidemiology of the staphylococci are not available in Nigeria. This study investigated 91 non-duplicate staphylococcal isolates obtained from the microbiology laboratories of eight hospitals in Nigeria during the period January to April 2010.
\end{abstract}

Methods: Identification and antibiotic susceptibility testing was performed using the VITEK 2 system, detection of resistance genes by PCR, and molecular characterization was determined by SCCmec typing, spa and multilocus sequence typing (MLST).

Results: All the isolates were susceptible to mupirocin, tigecycline, vancomycin and linezolid, but $72.5 \%$ of CNS and $82.3 \%$ of Staphylococcus aureus were resistant to cotrimoxazole, while multiresistance was observed in 37 of the 40 CNS isolates. Untypeable SCCmec types (ccrC/Class A mec and ccr-negative/Class C2 mec gene complex) in two methicillin-resistant S. aureus (MRSA) were identified. Additionally, ccr-negative/Class A mec and ccr type 4/ Class C2 mec gene complex was detected in one isolate each of S. sciuri and S. haemolyticus, respectively. The S. aureus isolates were classified into 21 spa types including two new types (t8987, t9008) among the methicillin-susceptible S. aureus (MSSA) isolates. Two (CC8-SCCmecnon-typeable and CC88-SCCmec IV) and four (CC8-SCCmec III/IVN; CC30-SCCmec II/III; CC88-SCCmec IV; and ST152-SCCmecnon-typeable) MRSA clones were identified in Maiduguri (North-East Nigeria) and South-West Nigeria, respectively. The proportion of Panton-Valentine leukocidin (PVL)-positive MSSA was high (44.4\%) and 56.3\% of these strains were associated with sequence type (ST) 152.

Conclusions: The identification of multiresistant mecA positive S. haemolyticus and S. sciuri from clinical samples indicates that characterization of CNS is important in providing information on their diversity and importance in Nigeria. There is the need to develop new SCCmec classification methods for non-typeable methicillin-resistant staphylococci, and to curtail the spread and establishment of the S. aureus ST152 clone in Nigeria. The study presents the first report of a PVL-positive ST152-SCCmecnontypeable MRSA and SCCmec typing of methicillin-resistant CNS in Nigeria.

Keywords: Coagulase negative staphylococci, Staphylococcus aureus, Multiresistance, mecA gene, Staphylococcus haemolyticus, Staphylococcus sciuri, Panton Valentine Leukocidin, SCCmec typing, ST152, Nigeria

\footnotetext{
* Correspondence: bayo_shittu@yahoo.com

'Department of Microbiology, Obafemi Awolowo University, lle-lfe, Nigeria

${ }^{2}$ Division of Medical Microbiology, University of Cape Town, Cape Town,

Republic of South Africa

Full list of author information is available at the end of the article
} 


\section{Background}

The staphylococci are part of the normal cutaneous ecosystem, but they are also opportunistic and invasive pathogens that cause a variety of human infections. Staphylococcus aureus is the most important human pathogen in this genus accounting for a high proportion of severe infections in hospitals and outpatient medical care [1-3]. Although the clinical relevance of coagulase negative staphylococci (CNS) is still controversial, patients at risk of CNS infections include neonates, those with intravascular catheters, prosthetic devices, postoperative sternal wound infections and immunocompromised hosts [4-7]. The remarkable ability of S. aureus and CNS to acquire antibiotic resistance limits therapeutic options, and morbidity and mortality rates of staphylococcal infections have increased the financial burden on health care systems worldwide [8-14].

Although there are reports on the characterization of staphylococci in Nigeria [15-18], many of the studies were limited to antibiotic susceptibility profiles. Moreover, one geographical region or health care institution was investigated, and CNS were not identified to species level. Only a few studies have investigated the molecular epidemiology and diversity of this group of organisms [19-23], however, they were not multi-centre surveys on S. aureus and CNS. This work describes a multi-centre study which was conducted in order to provide clinicians and infection control practitioners with information on antibiotic resistance profiles, molecular characteristics of coagulase positive and negative staphylococci, and to alert clinicians to the emergence of new clones in health care institutions (HCIs) in Nigeria.

\section{Methods}

Isolation and identification of staphylococcal isolatess

The study commenced with the request for nonduplicate staphylococcal isolates obtained from clinical samples processed in the microbiology laboratories of eight health care institutions in Ile-Ife, Ogbomosho, Iwo, Lagos (two centres) and Ibadan in South-West Nigeria; Jos in North-Central Nigeria, and Maiduguri in NorthEast Nigeria (Figure 1) during the period January to April, 2010. In this study, only staphylococcal isolates were analyzed and human subjects, clinical samples or human data were not investigated. All the hospitals, except the one located in Iwo, were tertiary health care institutions, each of which were at least 500-bed facilities providing medical care to about 500,000 to one million people. Preliminary verification as staphylococci was based on culture characteristics on blood agar, catalase, coagulase and DNase tests, while identification to species level was performed at the National Health Laboratory Service (NHLS), Groote Schuur Hospital, Cape
Town, South Africa using the VITEK 2 system (bioMérieux, France) with the Gram-Positive Identification Card.

\section{Antibiotic susceptibility testing}

Antibiotic susceptibility for penicillin G, oxacillin, teicoplanin, vancomycin, gentamicin, tetracycline, ciprofloxacin, moxifloxacin, trimethoprim/sulfamethoxazole (cotrimoxazole), fusidic acid, erythromycin, clindamycin, rifampicin, mupirocin, linezolid and tigecycline was determined by the broth microdilution method (VITEK 2 system, AST 603 cards, bioMérieux). S. aureus ATCC 29213 was the control strain and the VITEK 2 minimum inhibitory concentration (MIC) results were interpreted using the Advanced Expert System of the VITEK 2. Multiresistance was defined as resistance to at least three classes of antibiotics.

\section{DNA extraction}

Before DNA extraction, 5-8 colonies from an 18-24 h old culture on boiled blood agar was pretreated with lysostaphin (Sigma) $(20 \mu \mathrm{g} / \mathrm{ml}$ for S. aureus; $50 \mu \mathrm{g} / \mathrm{ml}$ for CNS) in $20 \mathrm{mM}$ Tris- $\mathrm{Cl}, 2 \mathrm{mM}$ EDTA at $37^{\circ} \mathrm{C}$ for $30 \mathrm{~min}$. The cells were harvested and DNA was isolated using a DNeasy tissue kit (Qiagen, Hilden, Germany).

\section{PCR detection of the tuf gene}

Phenotypic identification of the $S$. aureus isolates was confirmed by detection of the tuf gene as described previously [24]. The PCR products were detected by gel electrophoresis using $2 \% \mathrm{w} / \mathrm{v}$ agarose (Seakem, Whittaker, USA) and run in 1X TAE buffer ( $\mathrm{pH}$ 8.3) for $1 \mathrm{~h}$ at $100 \mathrm{~V}$. Thereafter, the gel was stained with ethidium bromide, visualized under UV light and photographed using a SynGene Bioimaging System.

\section{PCR detection of the dfrA gene}

The presence of the $d f r A$ gene encoding trimethoprim resistance was investigated using the primer pairs: dfrAF: AAT AGA CGT AAC GTC GTA CT; dfr-AR: AAG AAT GTA TGC GGT ATA GT and subsequent detection of a 289 bp product [25]. The PCR conditions were as follows: Initial denaturation at $95^{\circ} \mathrm{C}$ for $3 \mathrm{~min}$, followed by 30 cycles of amplification at $95^{\circ} \mathrm{C}$ for $30 \mathrm{~s}$, annealing at $55^{\circ} \mathrm{C}$ for $30 \mathrm{~s}$, extension at $72^{\circ} \mathrm{C}$ for $30 \mathrm{~s}$ and final extension at $72^{\circ} \mathrm{C}$ for $1 \mathrm{~min}$.

\section{SCCmec typing}

SCCmec typing was performed according to a previously published protocol [26] using the control strains $S$. aureus COL (type I), N315 (type II), ANS46 (type III), MW2 (type IV), WIS (type V) and HDE288 (type VI). For non-typeable SCCmec elements, the investigation of mec complexes and ccr allotypes as described by Kondo et al. [27] was carried out on representative 


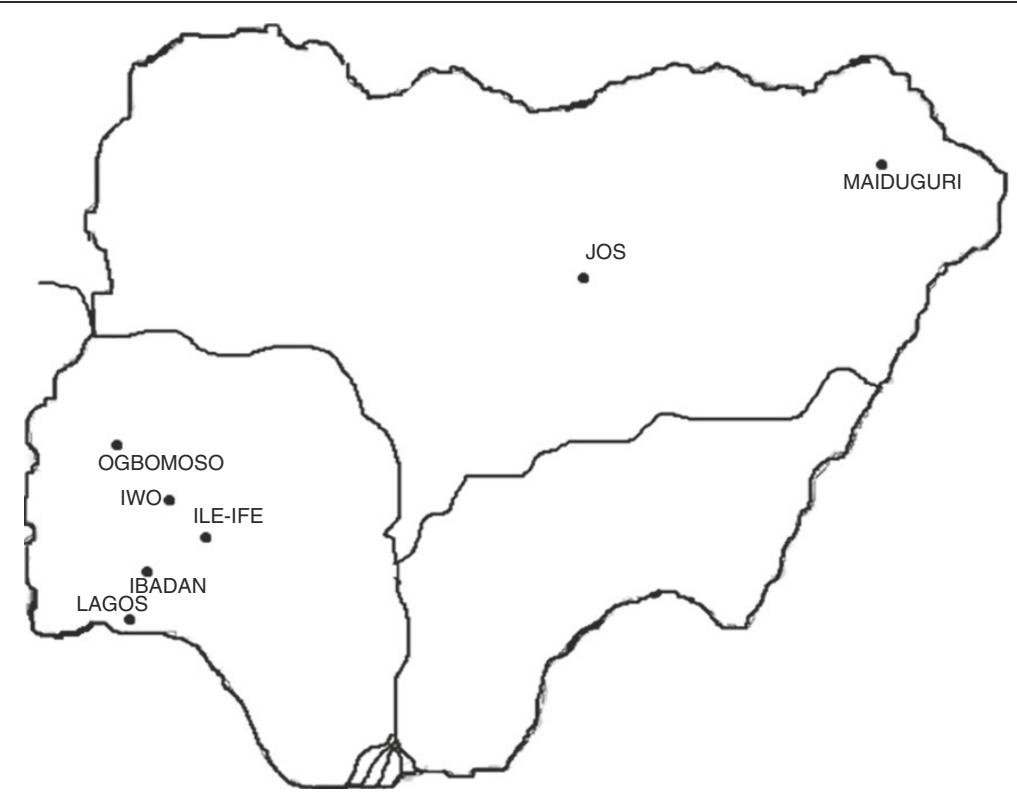

Figure 1 Map indicating the location of the health care institutions in Nigeria.

methicillin-resistant S. aureus (MRSA) and CNS isolates based on their spa-MLST profile and location of the health care institutions, respectively. The profiles obtained were characterized and defined according to the current nomenclature used for MRSA [28].

\section{Detection of the PVL gene}

The presence of the PVL gene was determined by PCR using primers luk-PV-1 and luk-PV-2 [29].

\section{Genotyping}

Typing of S. aureus was based on sequencing of the hypervariable region of the protein A gene $(s p a)$. The spa types were assigned using the Ridom StaphType (Ridom GmbH, Würzburg, Germany, version 1.5.21) [30]. Multilocus sequence typing (MLST) was carried out according to the protocols described previously [31] on a representative isolate for the predominant and new spa types. PCR products were purified and sequenced at the Central Analytical Facility at the University of Stellenbosch, South Africa. Allelic profiles and sequence types (STs) were assigned using the MLST S. aureus database (www.mlst.net). Isolates that were not typed by MLST were assigned STs based on the Based Upon Repeat Pattern (BURP) via the Ridom StaphType software.

\section{Results}

Identification and source of the staphylococcal isolates Preliminary verification of isolates obtained from the microbiology laboratories in eight HCIs in Nigeria identified 91 staphylococcal isolates $(51 \mathrm{~S}$. aureus and $40 \mathrm{CNS}$ ) and the characteristics of each isolate are presented in Tables 1, 2 and 3. The clinical S. aureus isolates were recovered from wounds, skin and soft tissue infections (SSI), osteomyelitis and burns (36.4\%), genitourinary tract infection (GTI)/infertility $(18.2 \%)$, septicaemia (15.9\%), urinary tract infection (UTI) (6.8\%), otitis media (6.8\%), bronchitis (4.5\%), and $11.4 \%$ were classified as other infections (Tables 1 and 2). Six species accounted for the CNS isolates: $S$. haemolyticus $(\mathrm{n}=21)$, S. sciuri $(\mathrm{n}=9)$, S. saprophyticus $(\mathrm{n}=5)$, S. warneri $(\mathrm{n}=3)$, S. epidermidis $(\mathrm{n}=1)$ and $S$. hominis $(\mathrm{n}=1)$, which were distributed across four HCIs located in Ogbomosho, Lagos (designated as Lagos2), Jos and Maiduguri (Table 3). Most of the S. haemolyticus isolates were from the centres in Lagos2, Jos and Maiduguri, and $47.6 \%$ of the isolates were obtained from septicaemia, $14.3 \%$ from wound infections, 9.5\% each from GTI, UTI, ocularrelated infections, and those categorised as other infections (Table 3).

\section{Antibiotic susceptibility of the staphylococcal isolates and detection of mecA and dfrA genes}

All the staphylococcal isolates were susceptible to mupirocin, tigecycline, vancomycin and linezolid (Table 4). In addition to the antibiotics stated above, the methicillinsusceptible $S$. aureus (MSSA) were susceptible to teicoplanin, gentamicin, erythromycin, clindamycin, fusidic acid and rifampicin. About $94 \%$ of MSSA were susceptible to the fluoroquinolones and one isolate was susceptible to all the antibiotics tested. However, $80.6 \%$ of MSSA were resistant to cotrimoxazole and penicillin, but all the cotrimoxazole-resistant MSSA were $d f r A$ negative. The predominant antibiotype was resistance to penicillin, 
Table 1 Characterization of MRSA from Nigeria by antibiotic resistance pattern, detection of genes and molecular typing

\begin{tabular}{|c|c|c|c|c|c|c|c|c|c|c|c|}
\hline $\begin{array}{l}\text { Isolate } \\
\text { No }\end{array}$ & Location & $\begin{array}{l}\text { Sample Or } \\
\text { Clinical Diagnosis }\end{array}$ & Antibiogram & $\begin{array}{l}\text { tuf } \\
\text { gene }\end{array}$ & $\begin{array}{l}\text { mecA } \\
\text { gene }\end{array}$ & $\begin{array}{l}\text { dfrA } \\
\text { gene }\end{array}$ & $\begin{array}{l}\mathrm{SCCmec} \\
\text { typing }\end{array}$ & $\begin{array}{l}\text { PVL } \\
\text { gene }\end{array}$ & $\begin{array}{l}\text { spa } \\
\text { type }\end{array}$ & $\begin{array}{c}\text { MLST } \\
\text { (ST) }\end{array}$ & $\begin{array}{c}\text { Clonal } \\
\text { Complex (CC) } \\
\end{array}$ \\
\hline 50 & Lagos1 & Burns & $\begin{array}{l}\text { PEN, OXA, GEN, CIP, MOX, } \\
\text { ERY, CLI*, TET, COT, RIF }\end{array}$ & + & + & + & III & - & t037 & ST241 & CC8 \\
\hline $2496^{\psi}$ & Maiduguri & GTI & $\begin{array}{l}\text { PEN, OXA, GEN, CIP, ERY, } \\
\text { CLI, TET, COT }\end{array}$ & + & + & - & NT/UNT & - & $\mathrm{t} 037^{* *}$ & & \\
\hline 2589 & Maiduguri & GTI & $\begin{array}{l}\text { PEN, OXA, GEN, CIP, ERY, } \\
\text { CLI, TET, COT }\end{array}$ & + & + & - & NT & - & t037 & & \\
\hline $60^{\psi}$ & Lagos1 & ASOM & PEN, OXA, TET, COT & + & + & - & NTN & - & t064** & ST8 & $\mathrm{CC} 8$ \\
\hline $69^{n}$ & Lagos1 & $\begin{array}{l}\text { Nasal swab/ } \\
\text { Screening }\end{array}$ & PEN, OXA, GEN, TET, COT & + & + & - & NT & - & t064 & & \\
\hline T39sB & Iwo & HIV/AIDS & PEN, OXA, TET, COT & + & + & - & NT & - & t064 & & \\
\hline T6530 & Ile-Ife & Osteomyelitis & PEN, OXA, GEN, CIP, TET, COT & + & + & - & IV & - & t064 & & \\
\hline TU32 & Ibadan & Wound Infection & PEN, OXA, CIP, TET, COT & + & + & - & NT & - & t064 & & \\
\hline TU3 $^{\psi}$ & Ibadan & Wound Infection & PEN, OXA, CIP, TET, COT & + & + & - & NTN & - & t064 & & \\
\hline $\mathrm{T5056}$ & Ile-Ife & Bronchitis & $\begin{array}{l}\text { PEN, OXA, GEN, CIP, ERY, } \\
\text { CLI*, TET, COT, FUS, RIF }\end{array}$ & + & + & - & III & - & t074 & ST37 & CC30 \\
\hline TD17 & Ile-Ife & Bronchitis & PEN, OXA, ERY, CLI & + & + & ND & $\|$ & - & t007 & ST39 & \\
\hline TN45 & Ile-Ife & Wound Infection & PEN, OXA, TET & + & + & ND & IV & - & t729 & ST88 & CC88 \\
\hline 003B & Maiduguri & Septicaemia & PEN, OXA, TET, COT & + & + & + & IV & - & t1603 & & \\
\hline 008 & Maiduguri & Septicaemia & PEN, OXA, COT & + & + & + & IV & - & $\mathrm{t} 1603$ & & \\
\hline T5843" & Ile-Ife & Osteomyelitis & PEN, OXA, TET, COT & + & + & - & NT/UNT & + & t4690** & ST152 & singleton \\
\hline
\end{tabular}

KEY:

$\Psi$ : Representative MRSA for SCCmec typing determined by Kondo et al. (2007).

१Nasal samples of health care workers (HCWs) in one of the hospitals in Lagos (designated as Lagos1).

Geographical region (Nigeria): South-West (Ile-Ife, Ibadan, Iwo and Lagos); North-East (Maiduguri); North Central (Jos).

GTI: Genital Tract Infection; ASOM: Acute suppurative otitis media.

Antibiotics - PEN: Penicillin; OXA: Oxacillin; GEN: Gentamicin; CIP: Ciprofloxacin; MOX: Moxifloxacin; ERY: Erythromycin; CLI: Clindamycin; TET: Tetracycline; FUS:

Fusidic acid; RIF: Rifampicin; COT: Cotrimoxazole; *: Inducible resistance (clindamycin).

UNT: Untypeable SCCmec types; NT: Non-typeable; ND: Not determined.

Isolates with spa type t007, t074, t729 and t1603 were assigned STs based on the Based Upon Repeat Pattern (BURP) via the Ridom StaphType software.

**: MLST on representative strains.

tetracycline and cotrimoxazole, which was observed in 14 isolates (39\%). Resistance to oxacillin was detected in $15 \mathrm{~S}$. aureus isolates and confirmed as MRSA by the detection of the mecA gene. Of the 15 MRSA isolates, 13 were resistant to cotrimoxazole and tetracycline, while 6 and 7 MRSA were resistant to gentamicin and ciprofloxacin, respectively. Two of the 5 erythromycin-resistant MRSA expressed inducible resistance to clindamycin. Overall, 12 of the 15 MRSA were resistant to at least three classes of antibiotics (Table 1). The trimethoprim resistance gene, $d f r A$, was detected in only 3 MRSA isolates.

All the S. haemolyticus isolates were resistant to penicillin, oxacillin and cotrimoxazole, but only one isolate exhibited resistance to fusidic acid. The proportion of S. haemolyticus isolates resistant to ciprofloxacin, gentamicin and tetracycline was $80.9 \%, 85.7 \%$ and $90.5 \%$, respectively (Table 4). Furthermore, $5(50 \%)$ of the 10 erythromycin-resistant $S$. haemolyticus isolates expressed inducible resistance to clindamycin, and one isolate showed intermediate resistance to teicoplanin (MIC: $16 \mu \mathrm{g} / \mathrm{ml})$. Multiresistant S. haemolyticus isolates were recovered from clinical samples in four HCIs in Lagos2, Maiduguri, Jos and Ogbomosho (Table 3). In contrast, resistance to fusidic acid was common in other species of CNS, and they were susceptible to erythromycin, clindamycin, teicoplanin and rifampicin (Table 4). The S. sciuri isolates were resistant to oxacillin and obtained primarily from various clinical samples in Ogbomosho (Table 3). On the whole, multiresistance was observed in 37 of the 40 CNS isolates, and the CNS isolates identified as methicillin-resistant (VITEK) were mecA positive.

\section{SCCmec typing}

Fifteen MRSA were obtained from the HCIs in Ile-Ife $(\mathrm{n}=5)$; Maiduguri $(\mathrm{n}=4)$; Lagos1 $(\mathrm{n}=3)$; Ibadan $(\mathrm{n}=2)$ and Iwo $(n=1)$. Using the multiplex typing method [26], SCCmec type IV was identified in two MRSA each from Ile-Ife and Maiduguri, SCCmec type III in two MRSA, one each from Ile-Ife and Lagos1, and SCCmec type II in one MRSA from Ile-Ife (Table 1). However, 8 of 15 MRSA and 28 methicillin-resistant CNS (MRCNS) were non-typeable. Based on another PCR-based method [27], 
Table 2 Characterization of MSSA from Nigeria by antibiotic resistance pattern, detection of genes and molecular typing

\begin{tabular}{|c|c|c|c|c|c|c|c|c|c|}
\hline $\begin{array}{l}\text { Isolate } \\
\text { No }\end{array}$ & Location & $\begin{array}{l}\text { Sample Or } \\
\text { Clinical Diagnosis }\end{array}$ & Antibiotype & $\begin{array}{l}\text { tuf } \\
\text { gene }\end{array}$ & $\begin{array}{l}\text { dfrA } \\
\text { gene }\end{array}$ & $\begin{array}{l}\text { PVL } \\
\text { gene }\end{array}$ & $\begin{array}{l}\text { spa } \\
\text { type }\end{array}$ & $\begin{array}{l}\text { MLST } \\
\text { (ST) }\end{array}$ & $\begin{array}{l}\text { Clonal } \\
\text { Complex (CC) }\end{array}$ \\
\hline 1229 & Maiduguri & GTI & TET & + & ND & - & $\mathrm{t} 311$ & ST5 & CC5 \\
\hline 652 & Maiduguri & Not available & PEN, COT & + & - & + & $\mathrm{t} 311$ & & \\
\hline 47 & Lagos1 & Leg Ulcer & PEN, TET, CIP, MOX, COT & + & - & - & t064 & & CC8 \\
\hline 54 & Lagos1 & SLE & PEN, TET, COT, CIP & + & - & - & t064 & & \\
\hline $49^{n}$ & Lagos 1 & Nasal swab/screening & PEN, COT & + & - & - & $\mathrm{t} 2331^{* *}$ & ST8 & \\
\hline 10 & Ogbomosho & $\mathrm{SSI}$ & PEN & + & ND & + & t084 & & CC15 \\
\hline 62 & Lagos 1 & UTI & COT & + & - & - & t084 & & \\
\hline 076 & Maiduguri & Not available & PEN, TET, COT & + & - & - & t084 & & \\
\hline 373 & Maiduguri & UTI & COT, TET & + & - & - & t084** & ST15 & \\
\hline 1253 & Maiduguri & SSI & PEN, TET, COT & + & - & - & t084 & & \\
\hline 2290 & Maiduguri & SSI & PEN, TET, COT & + & - & - & t084 & & \\
\hline 2696 & Maiduguri & Semen (Infertility) & PEN, COT & + & - & - & t084 & & \\
\hline 1038 & Maiduguri & SSI & PEN, COT & + & - & + & $\mathrm{t} 2216$ & & \\
\hline 2478 & Maiduguri & UTI & PEN, TET, COT & + & - & - & $\mathrm{t} 2216$ & & \\
\hline $6 \mathrm{~B}$ & Ogbomosho & Septicaemia & COT & + & - & + & t318 & ST30 & CC30 \\
\hline $51^{\natural}$ & Lagos1 & Nasal swab/screening & PEN, COT & + & - & - & $\mathrm{t} 318$ & & \\
\hline 1059 & Maiduguri & GTI & COT & + & - & - & t318 & & \\
\hline 2578 & Maiduguri & GTI & PEN, TET, COT & + & - & + & t934 & ST80 & CC80 \\
\hline 56 & Lagos1 & Otitis media & PEN, COT & + & - & - & t159 & ST121 & $\mathrm{CC} 121$ \\
\hline $67^{9}$ & Lagos1 & Nasal swab/screening & PEN, TET, COT & + & - & + & t2304 & & \\
\hline $68^{n}$ & Lagos1 & Nasal swab/screening & PEN, TET, COT & + & - & + & t2304 & & \\
\hline 006 & Maiduguri & Septicaemia & PEN, TET, COT & + & - & + & t355** & ST152 & singleton \\
\hline 0017 & Maiduguri & Septicaemia & PEN, TET, COT & + & - & + & t355 & & \\
\hline 1097 & Maiduguri & SSI & PEN, TET, COT & + & - & + & t355 & & \\
\hline 2365 & Maiduguri & Semen (Infertility) & PEN, COT & + & - & + & t355 & & \\
\hline 259 & Maiduguri & Semen (Infertility) & PEN, COT & + & - & + & t355 & & \\
\hline 604 & Maiduguri & SSI & PEN, TET, COT & + & - & - & t355 & & \\
\hline 642 & Maiduguri & SSI & PEN, TET & + & ND & + & t9008 & & \\
\hline 829 & Maiduguri & SSI & PEN, TET & + & ND & - & t9008 & & \\
\hline J11 & Jos & Septicaemia & PEN, TET, COT & + & - & + & t355 & & \\
\hline $\mathrm{J} 13$ & Jos & Septicaemia & PEN, TET, COT & + & - & + & $\mathrm{t} 355$ & & \\
\hline 61 & Lagos1 & SSI & TET, COT & + & - & + & t8987** & & \\
\hline $64^{9}$ & Lagos1 & Nasal swab/screening & PEN & + & $\mathrm{ND}$ & - & $\mathrm{t} 1510$ & ST508 & CC45 \\
\hline 55 & Lagos 1 & CSOM & PEN & + & ND & - & t8223 & ND & CC45 \\
\hline 57 & Lagos1 & Haematoma & Susceptible to all antibiotics & + & ND & - & t635 & ND & ND \\
\hline $70^{n}$ & Lagos1 & Nasal swab/screening & PEN, TET, COT & + & - & - & NT & ND & ND \\
\hline
\end{tabular}

KEY:

१: Nasal samples of health care workers (HCWs) in one of the hospitals in Lagos (designated as Lagos1).

GTI: Genital Tract Infection; SLE: systemic lupus erythematosus; SSI: Skin and soft tissue infection; UTI: Urinary Tract Infection; CSOM: Chronic suppurative otitis media.

Antibiotics - PEN: Penicillin; TET: Tetracycline; CIP: Ciprofloxacin; MOX: Moxifloxacin; COT: Cotrimoxazole.

ND: Not determined; NT: Non-typeable.

Spa types (bold) are new types; Isolates with spa type t064, t159, t311, t318, t934, 1510, t2216 and t2304 were assigned STs based on the Based Upon Repeat

Pattern (BURP) via the Ridom StaphType software. **: MLST on representative strains. 
Table 3 Identification and Characterization of CNS by antibiotic resistance pattern, mecA gene detection and SCCmec typing

\begin{tabular}{|c|c|c|c|c|c|c|}
\hline $\begin{array}{l}\text { Isolate } \\
\text { No }\end{array}$ & Location & $\begin{array}{l}\text { Sample/Clinical } \\
\text { Condition }\end{array}$ & $\begin{array}{l}\text { VITEK } 2 \\
\text { Identification }\end{array}$ & Antibiogram & $\begin{array}{l}\text { mecA } \\
\text { gene }\end{array}$ & $\begin{array}{l}\text { Sccmec } \\
\text { Typing }\end{array}$ \\
\hline 2 & Ogbomosho & Wound Infection & S. saprophyticus & PEN, TET, COT, FUS & - & ND \\
\hline 4 & Ogbomosho & UTI & S. saprophyticus & PEN, TET, COT, FUS & - & ND \\
\hline 7 & Ogbomosho & Osteomyelitis & S. saprophyticus & PEN, TET, COT, FUS & - & ND \\
\hline $13 B$ & Ogbomosho & UTI & S. saprophyticus & PEN, COT, FUS & - & ND \\
\hline $14^{\psi}$ & Ogbomosho & Septicaemia & S. sciuri & PEN, OXA, GEN, CIP, FUS, MOX & + & NT/UNT \\
\hline 16 & Ogbomosho & SSI & S. warneri & PEN, TET, COT, FUS & - & ND \\
\hline $16 B$ & Ogbomosho & Osteomyelitis & S. warneri & TET, COT, FUS & - & ND \\
\hline 18 & Ogbomosho & SSI & S. saprophyticus & PEN, TET, COT, FUS & - & ND \\
\hline 66 & Lagos2 & Wound Infection & S. sciuri & PEN, OXA, GEN, CIP, FUS & + & NT \\
\hline $\mathrm{L} 2^{\psi}$ & Lagos2 & Septicaemia & S. haemolyticus & PEN, OXA, TET, COT & + & NTN \\
\hline L5 & Lagos2 & Eye swab & S. haemolyticus & PEN, OXA, CIP, MOX, TET, COT & + & NT \\
\hline L6 & Lagos2 & Septicaemia & S. haemolyticus & PEN, OXA, GEN, CIP, ERY, TET, RIF, COT & + & NT \\
\hline L7 & Lagos2 & Septicaemia & S. haemolyticus & PEN, OXA, GEN, CIP, MOX, ERY, TET, COT & + & NT \\
\hline L8 & Lagos2 & Septicaemia & S. haemolyticus & PEN, OXA, GEN, CIP, ERY, CLI*, TET, COT & + & NT \\
\hline L9 & Lagos2 & Septicaemia & S. haemolyticus & PEN, OXA, GEN, CIP, TET, COT & + & NT \\
\hline L10 & Lagos2 & Eye swab & S. haemolyticus & PEN, OXA, GEN, CIP, MOX, ERY, TET, COT & + & NT \\
\hline 1103 & Maiduguri & Wound Infection & S. warneri & PEN, OXA, TET & + & NT \\
\hline 1268 & Maiduguri & Wound Infection & S. haemolyticus & PEN, OXA, GEN, CIP, MOX, TET, COT & + & NT \\
\hline $024^{\psi}$ & Maiduguri & Wound Infection & S. haemolyticus & PEN, OXA, GEN, TET, COT & + & NTN \\
\hline 2491 & Maiduguri & UTI & S. haemolyticus & PEN, OXA, GEN, CIP, ERY, TET, COT, TEICOi & + & NT \\
\hline 2412 & Maiduguri & Wound Infection & S. haemolyticus & PEN, OXA, GEN, CIP, MOX, TET, COT & + & NT \\
\hline $2362^{\psi}$ & Maiduguri & GTI & S. haemolyticus & PEN, OXA, GEN, CIP, ERY, CLI*, TET, COT & + & NT/UNT \\
\hline 825 & Maiduguri & GTI & S. haemolyticus & PEN, OXA, GEN, CIP, TET, COT & + & NT \\
\hline 2502 & Maiduguri & UTI & S. haemolyticus & PEN, OXA, GEN, COT & ND & ND \\
\hline$J 2$ & Jos & Septicaemia & S. hominis & PEN, OXA, TET & ND & ND \\
\hline$J 5$ & Jos & Septicaemia & S. haemolyticus & PEN, OXA, GEN, CIP, ERY, CLI*, TET, RIF, COT & ND & ND \\
\hline J6 & Jos & Septicaemia & S. haemolyticus & PEN, OXA, GEN, CIP, ERY, CLI*, TET, RIF, COT & ND & ND \\
\hline $\mathrm{J} 10$ & Jos & Septicaemia & S. haemolyticus & PEN, OXA, GEN, CIP, ERY, CLI*, TET, RIF, COT & ND & ND \\
\hline $\mathrm{J} 14^{\psi}$ & Jos & Septicaemia & S. haemolyticus & PEN, OXA, GEN, CIP, ERY, TET, FUS, COT & + & NTN \\
\hline J15 & Jos & Prostatis & S. haemolyticus & PEN, OXA, TET, COT & + & NT \\
\hline J16 & Jos & Otitis media & S. haemolyticus & PEN, OXA, GEN, CIP, COT & + & NT \\
\hline J17B & Jos & Osteomyelitis & S. epidermidis & PEN, OXA, COT & + & NT \\
\hline 151 & Ogbomosho & Septicaemia & S. haemolyticus & PEN, OXA, GEN, CIP, MOX, TET, COT & + & NT \\
\hline 12 & Ogbomosho & Conjunctivitis & S. sciuri & PEN, OXA, GEN, CIP, FUS & + & NT \\
\hline $19 B$ & Ogbomosho & SSI & S. sciuri & PEN, OXA, GEN, CIP, TET, FUS & + & NT \\
\hline 11 & Ogbomosho & Wound abscess & S. sciuri & PEN, OXA, GEN, CIP, FUS & + & NT \\
\hline 17 & Ogbomosho & Wound infection & S. sciuri & PEN, OXA, CIP, GEN, FUS & + & NT \\
\hline $11 \mathrm{~B}$ & Ogbomosho & UTI & S. sciuri & PEN, OXA, GEN, CIP, MOX, FUS & + & NT \\
\hline 15 & Ogbomosho & UTI & S. sciuri & PEN, OXA, GEN, CIP, MOX, FUS & + & NT \\
\hline 6 & Ogbomosho & UTI & S. sciuri & PEN, OXA, GEN, CIP, FUS & + & NT \\
\hline
\end{tabular}

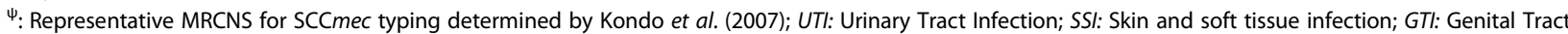
Infection. Antibiotics - PEN: Penicillin; OXA: Oxacillin; GEN: Gentamicin; CIP: Ciprofloxacin; MOX: Moxifloxacin; ERY: Erythromycin; CLI: Clindamycin; TET: Tetracycline; FUS: Fusidic acid; RIF: Rifampicin; COT: Cotrimoxazole; TEICO: Teicoplanin. *: Inducible resistance (clindamycin); ND: Not determined; NT: Non-typeable; UNT: Untypeable SCCmec types. 
Table 4 Antibiotic resistance profile of staphylococci from Nigeria

\begin{tabular}{|c|c|c|c|c|}
\hline \multirow[b]{2}{*}{ Antibiotics } & \multicolumn{4}{|c|}{ Number (\%) of isolates resistant among } \\
\hline & MSSA & MRSA & S. haemolyticus & Others (CNS) \\
\hline & $n=36$ & $n=15$ & $\mathrm{n}=21$ & $\mathrm{n}=19$ \\
\hline Penicillin & $29(80.6)$ & $15(100)$ & $21(100)$ & $18(94.7)$ \\
\hline Oxacillin & $0(0)$ & $15(100)$ & $21(100)$ & $12(63.2)$ \\
\hline Teicoplanin & $0(0)$ & $0(0)$ & $1^{*}(4.8)$ & $0(0)$ \\
\hline Vancomycin & $0(0)$ & $0(00$ & $0(0)$ & $0(0)$ \\
\hline Gentamicin & $0(0)$ & $6(40)$ & $18(85.7)$ & $9(47.4)$ \\
\hline Tetracycline & $21(58.3)$ & $13(86.7)$ & $19(90.5)$ & $9(47.4)$ \\
\hline Ciprofloxacin & $2(5.6)$ & $7(46.7)$ & $17(80.9)$ & $9(47.4)$ \\
\hline Moxifloxacin & $1(2.8)$ & $1(6.7)$ & $6(28.6)$ & $3(15.8)$ \\
\hline Erythromycin & $0(0)$ & $5(33.3)$ & $10(47.6)$ & $0(0)$ \\
\hline Clindamycin & $0(0)$ & 5 (33.3) & $5(23.8)$ & $0(0)$ \\
\hline Fusidic acid & $0(0)$ & $1(6.7)$ & $1(4.8)$ & $16(84.2)$ \\
\hline Tigecycline & $0(0)$ & $0(0)$ & $0(0)$ & $0(0)$ \\
\hline Mupirocin & $0(0)$ & $0(0)$ & $0(0)$ & $0(0)$ \\
\hline Linezolid & $0(0)$ & $0(0)$ & $0(0)$ & $0(0)$ \\
\hline Rifampicin & $0(0)$ & $2(13.3)$ & $4(19)$ & $0(0)$ \\
\hline Cotrimoxazole & 29 (80.6) & $13(86.7)$ & $21(100)$ & $8(42.1)$ \\
\hline
\end{tabular}

*Intermediate resistance.

two of the four representative MRSA and three $S$. haemolyticus possessed the SCCmec V element (ccrC/Class $\mathrm{C} 2 \mathrm{mec}$ ). However, untypeable $\mathrm{SCC} m e c$ elements were detected in two MRSA (ccrC/Class A mec and ccrnegative/Class $\mathrm{C} 2 \mathrm{mec}$ ) and one isolate each of $\mathrm{S}$. sciuri and S. haemolyticus (ccr-negative/Class A mec and ccr type 4/Class C2 mec gene complex) (Tables 1 and 3).

\section{Detection of PVL gene}

One MRSA from Ile-Ife was PVL positive (Table 1). The gene was also detected in 16 MSSA, of which 10 were isolated from patients with SSI and septicaemia (Table 2).

\section{Molecular typing of MSSA and MRSA}

A total of 21 spa types were identified and representative $S$. aureus strains assigned as t037, t064, t084, t355, t2331, t4690, and new types t8987 and t9008 were selected for MLST (Tables 1 and 2). In MRSA, seven different spa types were identified and isolates with spa types t037, t064, and t4690 were assigned ST241, ST8 and ST152, respectively. Overall, the clonal complexes for MRSA were distributed across CC8, CC30, CC88 and ST152 (Table 2). In MSSA, fifteen different spa types, including two new types (t8987 and t9008) were identified of which only t064 was identified also in MRSA (Tables 1 and 2). The predominant spa types were t355 (8 isolates), t084 (7 isolates) and t318 (3 isolates) and a diversity of spa types (t318, t1510, t2304, t2331, spa non-typeable) were identified among the MSSA from nasal samples of health care workers (HCWs) (Table 2). MSSA isolates with spa type t084 and 2331 were assigned ST15 and ST8 respectively, while ST152 accounted for the new spa types (t8987, t9008) and t355. Nine and 11 of the 36 MSSA clustered with ST15 and ST152 respectively (Table 2).

\section{Discussion}

The identification of bacterial isolates to species level is of great importance in the clinical microbiology laboratory to obtain information on the diversity and significance of each species in human infection. Moreover, species identification is a prerequisite for epidemiological studies. Many clinical microbiology laboratories in Nigeria do not identify staphylococci (in particular CNS) to species level, which is important in understanding their variety and clinical relevance. Two species, S. haemolyticus and S. sciuri, accounted for the majority of the 40 CNS isolates investigated in this study (Table 3). Most of the $S$. haemolyticus isolates were obtained from blood culture samples in HCIs in Lagos2 and Jos, and S. sciuri from samples in Ogbomosho (South-West Nigeria). S. haemolyticus is regarded as the second most frequently isolated staphylococci from blood cultures [32] and one of the most clinically relevant CNS, particularly in immunocompromised patients [33]. S. sciuri, principally found in animal species, and although not considered important from the clinical standpoint, has been associated with infections such as endocarditis [34], urinary tract infection [35] and wound infections $[19,36]$. Multiresistance to antibiotics was detected in 37 of the $40 \mathrm{CNS}$ isolates, and all the S. haemolyticus isolates were resistant to at least three classes of antibiotics. Apart from the possible clinical importance because of its serious impact on the course of infection, multiresistant CNS are a potential source of genes encoding resistance to antibiotics for other staphylococci pathogenic for man. The isolation of multiresistant mecA positive S. haemolyticus from blood samples (septicaemia) and S. sciuri from various clinical materials (Table 3) in some HCIs clearly indicate that they could be of clinical importance in Nigeria. A number of reports have indicated an increase in the resistance of staphylococci to cotrimoxazole in Nigeria $[15,18,21,23,37]$. In this study, $72.5 \%$ of $\mathrm{CNS}$ and $82.3 \%$ of $S$. aureus isolates were resistant to cotrimoxazole. The antibiotic has wide clinical application, inexpensive, orally administered and available over-the-counter where they are sold with or without prescription in Nigeria. This could possibly explain the high level of staphylococcal resistance observed in this study. Most of the cotrimoxazoleresistant $S$. aureus were $d f r A$-negative; hence more 
studies are needed to understand the molecular mechanism of resistance in Nigeria.

Methicillin resistance in staphylococci is due to the expression of the mecA gene, which mediates penicillin binding protein $2 \mathrm{a}(\mathrm{PBP} 2 \mathrm{a})$, a transpeptidase with low affinity for beta-lactams $[7,38]$. The mecA gene is carried by a mobile genetic element (MGE) termed the staphylococcal cassette chromosome (SCCmec), and though the mec origin remains unknown, it has been suggested that $m e c A$ CNS may act as potential SCCmec donor accounting for the rise of new MRSA clones [39]. Eleven SCCmec elements have been described to date: SCCmec I-IV [40-42], and V-XI [43-48], but few reports exist on the detection of $m e c A$ gene and characterization of SCCmec types in Nigeria [21-23]. There was excellent correlation between results of antibiotic susceptibility testing (VITEK) and detection of the mecA gene for the confirmation of methicillin-resistant staphylococci. However, the MRCNS were non-typeable using the multiplex PCR protocol [26]. Based on the method of Kondo et al. [27], the SCCmec V element (ccrC/Class $\mathrm{C} 2 \mathrm{mec}$ ) was identified in representative $S$. haemolyticus isolates, as well as untypeable $\mathrm{SCCmec}$ elements (ccrnegative/Class A mec and ccr type 4/Class C2 mec gene complex) in one representative isolate each of $S$. sciuri and S. haemolyticus (Table 3). Recent studies have indicated that SCCmec V is the predominant element among methicillin-resistant $S$. haemolyticus isolates $[33,49]$. To the best of our knowledge, this is the first report on the characterization of SCCmec elements in CNS in Nigeria. It is likely that the mec gene complex and $c c r$ genes in CNS are diverse and distinct, and as indicated in previous reports $[7,28]$, there is the need to develop new classification schemes for non-typeable SCCmec types in MRCNS.

Molecular typing of the MRSA isolates indicated that two clones (CC8-SCCmecnon-typeable and CC88SCCmec IV) existed in Maiduguri, North-East Nigeria, and four clones in South-West Nigeria (CC8-SCCmecIII/ IV/V; CC30-SCCmecII/III; CC88-SCCmecIV and ST152SCCmecnon-typeable) (Table 1). Previous studies on the epidemiology of MRSA in Nigeria identified MRSA clones t064-ST8-CC8 and t037-ST241-CC8 in SouthWest and North-East Nigeria, respectively [22,23]. A community-associated clone, CC88-MRSA-IV, previously reported in Ibadan, Nigeria [21] was identified from wound and blood samples in Maiduguri and Ile-Ife, however, we were unable to determine whether the isolates were community-associated. Untypeable SCCmec types (ccrC/Class A mec; $c c r$-negative/Class $\mathrm{C} 2 \mathrm{mec}$ ) were detected in two representative MRSA isolates, of which one was a PVL-positive isolate (t4690-ST152) from a patient with osteomyelitis in Ile-Ife (South-West Nigeria).
The MSSA were assigned mainly to clonal complexes CC5, CC8, CC15, CC30, CC45, CC80 and ST152 (Table 2). A high proportion of MSSA from Maiduguri were grouped in ST15 or ST152 indicating that these clones were successful in North East Nigeria. PVLencoding genes were detected in 16 MSSA (44.4\%) isolates belonging to almost all clonal complexes identified in this study. Moreover, $56 \%$ of these strains were associated with ST152 and 10 of 16 (62.5\%) PVL positive MSSA isolates were associated with SSI and septicaemia. These observations confirm previous studies that PVLpositive MSSA ST152 are widespread in African countries [50-52] including Nigeria [22,23]. Furthermore, MSSA isolates (ST121) from nasal samples of HCWs were PVL positive. Our data suggests that the sequence types for pandemic PVL-positive MSSA identified in this study did not function as a reservoir for PVL-positive MRSA supporting the argument of Schaumburg et al. [52] that the intimate inter-relation between PVL-positive MSSA and MRSA, which could lead to the emergence and spread of PVL-positive MRSA clones has not been established. However, the detection of an ST152-PVLpositive MRSA in this study suggests that surveillance for this clone is strongly advocated in Nigeria.

\section{Conclusions}

This is the first multi-centre study on the characterization of coagulase positive and negative staphylococci using phenotypic and molecular methods in Nigeria. However, there were a number of limitations in this study. The number of isolates from the HCIs was low and variable which did not allow for comparison of data among the participating centres. Moreover, the diversity of the staphylococci analysed in this study does not represent their distribution patterns in health care institutions in Nigeria. Lastly, we could not conduct full characterization of the mecA-positive CNS isolates, and only representative isolates were selected for SCCmec typing and MLST. However, this study has highlighted the importance of species identification for CNS, their clinical relevance, and the need for longitudinal multi-centre surveys to provide data on antibiotic resistance and epidemiology of the staphylococci in Nigeria. Characterization of multiresistant mecA positive S. haemolyticus and S. sciuri from clinical samples is important in understanding their epidemiology within hospitals in Nigeria. The identification of untypeable SCCmec types in the study will be further evaluated and characterized; however, there is the need to develop new SCCmec classification schemes for nontypeable methicillin-resistant staphylococci. There is an urgent need to curtail the spread and establishment of PVL-positive MSSA, in particular, the MSSA ST152 clone, in Nigeria. 


\section{Abbreviations}

SCCmec: Staphylococcal Cassette Chromosome mec; CC: Clonal Complex; PVL: Panton Valentine Leukocidin; ST: Sequence type; CNS: Coagulase negative staphylococci; HCls: Health Care Institutions; MIC: Minimum Inhibitory Concentration; MLST: Multilocus sequence typing; ASOM: Acute suppurative otitis media; CSOM: Chronic suppurative otitis media; SLE: Systemic lupus erythematosus; GTI: Genitourinary tract infection; UTI: Urinary tract infection; SSI: Skin and soft tissue infection; MSSA: Methicillin-susceptible Staphylococcus aureus; MRSA: Methicillinresistant Staphylococcus aureus; MRCNS: Methicillin-resistant coagulase negative staphylococci; NT: Non-typeable; ND: Not determined; UNT: Untypeable; Antibiotics: ; PEN: Penicillin; OXA: Oxacillin; TEICO: Teicoplanin; TET: Tetracycline; GEN: Gentamicin; CIP: Ciprofloxacin; MOX: Moxifloxacin; ERY: Erythromycin; CLI: Clindamycin; FUS: Fusidic acid; RIF: Rifampicin; COT: Cotrimoxazole.

\section{Competing interests}

The authors declare that they have no competing interest.

\section{Authors' contributions}

$\mathrm{AOS}, \mathrm{KO}, \mathrm{AR}, \mathrm{ST}, \mathrm{FO}, \mathrm{KO}$ and GE participated in the design of the study. OO and FA performed the preliminary identification of the isolates. AOS carried out the molecular characterization of the isolates. All authors read and approved the final manuscript.

\section{Acknowledgments}

We would like to thank the management of the hospitals for their support in the collection of the staphylococcal isolates. We also appreciate the assistance of Professor Mark Nicol, Dr. Eliya Madikane, Melissa Jansen van Rensburg, Malefu Moleleki (Division of Medical Microbiology, University of Cape Town, South Africa), staff of the National Health Laboratory Service (NHLS, Groote Schuur Hospital, Cape Town, South Africa), Dr Franziska Layer (Staphylococcal Reference Centre, Robert Koch Institute, Wernigerode, Germany), Professor Teruyo Ito and Dr. Xiao Han of the Department of Bacteriology, Juntendo University, Japan. We appreciate the comments and suggestions of Drs Edet Udo, Birgit Strommenger, Ulrich Nübel and Professor Iruka Okeke in the preparation of the manuscript. The research visit of AOS to the Division of Medical Microbiology, University of Cape Town, South Africa was supported by the visitor's award by Clinical Infectious Disease Research Initiative (CIDRI).

\section{Author details}

${ }^{1}$ Department of Microbiology, Obafemi Awolowo University, Ile-Ife, Nigeria. ${ }^{2}$ Division of Medical Microbiology, University of Cape Town, Cape Town, Republic of South Africa. ${ }^{3}$ Department of Biological Sciences, College of Science, Engineering and Technology, Osun State University, Osogbo, Nigeria. ${ }^{4}$ Department of Medical Microbiology, University of Maiduguri Teaching Hospital, Maiduguri, Nigeria. ${ }^{5}$ Department of Medical Microbiology and Parasitology, Lagos State University Teaching Hospital, Lagos, Nigeria. ${ }^{6}$ Department of Medical Microbiology and Parasitology, Ladoke Akintola University of Technology Teaching Hospital, Ogbomosho, Nigeria. ${ }^{7}$ Department of Medical Microbiology and Parasitology, College of Medicine, University of Lagos, Lagos, Nigeria. ${ }^{8}$ Department of Medical Microbiology and Parasitology, Jos University Teaching Hospital, Jos, Nigeria.

Received: 28 May 2012 Accepted: 29 October 2012

Published: 2 November 2012

\section{References}

1. Chambers HF, Deleo FR: Waves of resistance: Staphylococcus aureus in the antibiotic era. Nat Rev Microbiol 2009, 7(9):629-641.

2. Nickerson EK, West TE, Day NP, Peacock SJ: Staphylococcus aureus disease and drug resistance in resource-limited countries in South and East Asia. Lancet Infect Dis 2009, 9(2):130-135.

3. Fry DE, Barie PS: The changing face of Staphylococcus aureus: a continuing surgical challenge. Surg Infect (Larchmt) 2011, 12(3):191-203.

4. Huebner J, Goldmann DA: Coagulase-negative staphylococci: role as pathogens. Ann Rev Med 1999, 50:223-236.

5. O'Gara JP, Humpreys H: Staphylococcus epidermidis biofilms: importance and implications. J Med Microbiol 2001, 50(7):582-587.
6. Deepa S, Kumari A, Venkatesha D: Increasing trends of methicillin resistant coagulase negative Staphylococcus in neonatal septicaemia a study in a tertiary care hospital, Mysore, South India. OJHAS 2010, 9(4):1-3.

7. Zong Z, Peng C, Lu X: Diversity of SCCmec elements in methicillinresistant coagulase-negative staphylococci clinical isolates. PLoS One 2011, 6(5):e20191.

8. Venkatesh MP, Placencia F, Weisman LE: Coagulase negative staphylococcal infections in the neonate and child: an update. Semin Pediatr Infect Dis 2006, 17(3):120-127.

9. Anderson-Berry A, Brinton B, Lyden E, Faix RG: Risk factors associated with development of persistent coagulase negative staphylococci bacteremia in the neonate and associated short-term and discharge morbidities. Neonatology 2011, 99(1):23-31.

10. Bassetti M, Trecharichi EM, Mesini A, Spanu T, Giacobbe DR, Rossi M, Shenone E, Pascale GD, Molinari MP, Cauda R, Viscoli C, Tumbarello M: Risk factors and mortality of healthcare-associated and community-acquired Staphylococcus aureus bacteraemia. Clin Microbiol Infect 2011, doi:10.1111/ j.1469-0691.2011.03679. Epub ahead of print

11. de Kraker ME, Davey PG, Grundmann H, on behalf of the BURDEN study group: Mortality and hospital stay associated with resistant Staphylococcus aureus and Escherichia coli bacteremia: estimating the burden of antibiotic resistance in Europe. PLoS Med 2011, 8(10):e1001104

12. Jain A, Agarwal A, Verma RK, Awasthi S, Singh KP: Intravenous device associated blood stream staphylococcal infection in paediatric patients. Indian J Med Res 2011, 134(2):193-199.

13. Jean-Baptiste N, Benjamin DK Jr, Cohen-Wolkowiez M, Fowler VG Jr, Laughon M, Clark RH Smith PB: Coagulase negative staphylococcal infections in the neonatal intensive care unit. Infect Control Hosp Epidemiol 2011, 32(7):679-686.

14. Marra AR, Camargo LF, Pignatari AC, Sukiennik T, Behar PR, Medeiros EA, Ribeiro J, Girão E, Correa L, Guerra C, Brites C, Pereira CA, Carneiro I, Reis M, de Souza MA, Tranchesi R, Barata CU, Edmond MB, Brazilian SCOPE Study Group: Nosocomial bloodstream infections in Brazilian hospitals: analysis of 2,563 cases from a prospective nationwide surveillance study. J Clin Microbiol 2011, 49(5):1866-1871.

15. Akinkunmi EO, Lamikanra A: Species distribution and antibiotic resistance in coagulase negative staphylococci colonizing the gastrointestinal tract of children in Ile-Ife, Nigeria. Trop J Pharm Res 2010, 9(1):35-43.

16. Akinjogunla OJ, Enabulele $1 \mathrm{O}$ : Virulence factors, plasmid profiling and curing analysis of multidrug resistant Staphylococcus aureus and coagulase negative Staphylococcus spp. isolated from patients with acute otitis media. J American Sci 2010, 6(11):1022-1033.

17. Efuntoye MO: Study of antibiotic sensitivity pattern and enterotoxigenicity of staphylococci isolated from swimming pools in Ibadan, Nigeria. World App/ Sci J 2010, 9(11):1324-1327.

18. Jombo GTA, Akpan S, Epoke J, Akaa PD, Eyong Kl, Gyuse AN, Okwori EE, Etukumana EA: Antimicrobial susceptibility profile of community acquired and nosocomial isolates of Staphylococcus aureus and that of coagulase negative staphylococci from clinical blood culture specimens at a Nigerian University Teaching Hospital. J Clin Med Res 2010, 2(6):83-90.

19. Shittu AO, Lin J, Morrison D, Kolawole DO: Isolation and molecular characterization of multiresistant Staphylococcus sciuri and Staphylococcus haemolyticus associated with skin and soft-tissue infections. J Med Microbiol 2004, 53(Pt1):51-55.

20. Shittu AO, Lin J, Morrison D, Kolawole DO: Identification and molecular characterization of mannitol positive, coagulase negative staphylococci from nasal samples of medical personnel and students. J Med Microbiol 2006, 55(Pt3):317-324

21. Ghebremedhin B, Olugbosi MO, Raji AM, Layer F, Bakare RA, König B, König W: Emergence of a community-associated methicillin-resistant Staphylococcus aureus strain with a unique resistance profile in Southwest Nigeria. J Clin Microbio/ 2009, 47(9):2975-2980.

22. Okon $\mathrm{KO}$, Basset $\mathrm{P}$, Uba A, Lin J, Shittu AO, Blanc DS: Co-occurrence of predominant Panton-Valentine leukocidin-positive sequence type (ST) 152 and multi-drug resistant ST241 Staphylococcus aureus clones in Nigerian hospitals. J Clin Microbiol 2009, 47(9):3000-3003.

23. Shittu AO, Okon K, Adesida S, Oyedara O, Witte W, Strommenger B, Layer F, Nübel $U$ : Antibiotic resistance and molecular epidemiology of Staphylococcus aureus in Nigeria. BMC Microbio/ 2011, 11:92. 
24. Martineau F, Picard FJ, Ke D, Paradis S, Roy PH, Ouellette M, Bergeron MG: Development of a PCR assay for identification of staphylococci at genus and species levels. J Clin Microbiol 2001, 39(7):2541-2547.

25. Ender $\mathrm{M}$, Berger-Bächi $\mathrm{B}, \mathrm{McC}$ allum $\mathrm{N}$ : Variability in $\mathrm{SCCmec}_{\mathrm{N} 1}$ spreading among injection drug users in Zurich, Switzerland. BMC Microbiol 2007, 7:62.

26. Milheiriço C, Oliveira DC, de Lencastre H: Update to the multiplex PCR strategy for assignment of mec element types in Staphylococcus aureus. Antimicrob Agents Chemother 2007, 51(9):3374-3377. Epub 2007 Jun 18. Erratum in: Antimicrob Agents Chemother 2007, 51(12):4537.

27. Kondo Y, Ito T, Ma XX, Watanabe S, Kreiswirth BN, Etienne J, Hiramatsu K: Combination of multiplex PCRs for staphylococcal cassette chromosome mec type assignment: rapid identification system for mec, ccr and major differences in junkyard regions. Antimicrob Agents Chemother 2007, 51(1):264-274.

28. International Working Group on the classification of Staphylococcal Cassette Chromosome elements (IWG-SCC): Classification of staphylococcal cassette chromosome mec (SCCmec): guidelines for reporting novel SCCmec elements. Antimicrob Agents Chemother 2009, 53(12):4961-4967.

29. Lina G, Piémont Y, Godail-Gamot F, Bes M, Peter MO, Gauduchon V, Vandenesch F, Etienne J: Involvement of Panton-Valentine LeukocidinProducing Staphylococcus aureus in Primary Skin Infections and Pneumonia. Clin Infect Dis 1999, 29(5):1128-1132.

30. Harmsen D, Claus H, Witte W, Rothgänger J, Claus H, Turnwald D, Vogel U: Typing of methicillin-resistant Staphylococcus aureus in a university setting by using novel software for spa repeat determination and database management. J Clin Microbiol 2003, 41(12):5442-5448.

31. Enright MC, Day NP, Davies CE, Peacock SJ, Spratt BG: Multilocus sequence typing for characterization of methicillin-resistant and methicillin-susceptible clones of Staphylococcus aureus. J Clin Microbiol 2000, 38(3):1008-1015

32. Ing MB, Baddour LM, Bayer AS: Bacteremia and infective endocarditis: pathogenesis, diagnosis, and complications. In The Staphylococci In Human Disease. Edited by Crossley KB, Archer GL. New York: Churchill Livingstone; 1997:331-354.

33. Bouchami $\mathrm{O}$, Ben Hassen $\mathrm{A}$, de Lencastre $\mathrm{H}$, Miragaia M: High prevalence of mec complex $\mathrm{C}$ and $\mathrm{ccrC}$ is independent of SCCmec type $\mathrm{V}$ in Staphylococcus haemolyticus. Eur J Clin Microbiol Infect Dis 2012, 31(4):605-614

34. Wallet F, Stuit $L$, Boulanger $E$, Roussel-Delvallez M, Dequiedt $P$ Courcol RJ: Peritonitis due to Staphylococcus sciuri in a patient on continuous ambulatory peritoneal dialysis. Scand J Infect Dis 2000, 32(6):697-698.

35. Stepanovic S, Jezek P, Vukovic D, Dakic I, Petras P: Isolation of members of the Staphylococcus sciuri group from urine and their relationship to urinary tract infections. J Clin Microbiol 2003, 41(11):5262-5264.

36. Coimbra DG, Almeida AGCS, Júnior JBO, da Silva AF, Pimentel BJ, Gitaí DLG, Moreira LS, Silva-Filho EA, de Andrade TG: Wound infection by multiresistant Staphylococcus sciuri identified by molecular methods. New Microbiol 2011, 34(4):425-427.

37. Shittu AO, Lin J, Kolawole DO: Antimicrobial susceptibility patterns of Staphylococcus aureus and characterization of MRSA in Southwestern Nigeria. WOUNDS 2006, 18(4):77-84.

38. Garza-González E, Morfin-Otero R, Llaca-Diaz JM, Rodriguez-Noriega E: Staphylococcal cassette chromosome (SCCmec) in methicillin-resistant coagulase negative staphylococci. A review and the experience in a tertiary-care setting. Epidemiol Infect 2010, 138(5):645-654.

39. Hanssen AM, Ericson Sollid JU: SCCmec in staphylococci: genes on the move. FEMS Immunol Med Microbiol 2006, 46(1):8-20.

40. Ito $T$, Katayama $Y$, Hiramatsu $K$ : Cloning and nucleotide sequence determination of the entire mec DNA of pre-methicillin-resistant Staphylococcus aureus N315. Antimicrob Agents Chemother 1999, 43 (6):1449-1458.

41. Ito T, Katayama Y, Asada K, Mori N, Tsutsumimoto K, Tiensasitorn C, Hiramatsu K: Structural comparison of three types of staphylococcal cassette chromosome mec integrated in the chromosome in methicillin-resistant Staphylococcus aureus. Antimicrob Agents Chemother 2001, 45(5):1323-1336.

42. Ma XX, Ito T, Tiensasitorn C, Jamklang M, Chongtrakool P, Boyle-Vavra S, Daum RS, Hiramatsu K: Novel type of staphylococcal cassette chromosome mec identified in community-acquired methicillin-resistant
Staphylococcus aureus strains. Antimicrob Agents Chemother 2002, 46(4):1147-1152.

43. Ito T, Ma XX, Takeuchi F, Okuma K, Yuzawa H, Hiramatsu K: Novel type V staphylococcal cassette chromosome mec driven by a novel cassette chromosome recombinase, ccrC. Antimicrob Agents Chemother 2004, 48(7):2637-2651.

44. Oliveira DC, Milheiriço C, de Lencastre $H$ : Redefining a structural variant of staphylococcal cassette chromosome mec, SCCmec type VI. Antimicrob Agents Chemother 2006, 50(10):3457-3459.

45. Berglund C, Ito T, Ikeda M, Ma XX, Söderquist B, Hiramatsu K: Novel type of staphylococcal cassette chromosome mec in a methicillin-resistant Staphylococcus aureus strain isolated in Sweden. Antimicrob Agents Chemother 2008, 52(10):3512-3516.

46. Zhang K, McClure JA, Elsayed S, Conly JM: Novel staphylococcal cassette chromosome mec type, tentatively designated type VIII, harboring class A mec and type $4 \mathrm{ccr}$ gene complexes in a Canadian epidemic strain of methicillin-resistant Staphylococcus aureus. Antimicrob Agents Chemother 2009, 53(2):531-540.

47. Li S, Skov RL, Han X, Larsen AR, Larsen J, Sørum M, Wulf M, Voss A Hiramatsu K, Ito T: Novel types of staphylococcal cassette chromosome mec elements identified in clonal complex 398 methicillin resistant Staphylococcus aureus strains. Antimicrob Agents Chemother 2011, 55(6):3046-3050.

48. Shore AC, Deasy EC, Slickers P, Brennan G, O'Connell B, Monecke S, Ehricht $R$, Coleman DC: Detection of staphylococcal cassette chromosome mec type XI carrying highly divergent mecA, mecl, mecR1, blaZ, and ccr genes in human clinical isolates of clonal complex 130 methicillin-resistant Staphylococcus aureus. Antimicrob Agents Chemother 2011, 55(8):3765-3773.

49. Barros EM, Ceotto H, Bastos MCF, dos Santos KRN, Giambiagi-deMarval M: Staphylococcus haemolyticus as an important hospital pathogen and carrier of methicillin resistance genes. J Clin Microbiol 2012, 50(1):166-168.

50. Ruimy R, Maiga A, Armand-Lefevre L, Maiga I, Diallo A, Koumaré AK, Ouattara K, Soumaré S, Gaillard K, Lucet JC, Andremont A, Feil EJ: The carriage population of Staphylococcus aureus from Mali is composed of a combination of pandemic clones and the divergent Panton-Valentine leukocidin-positive genotype ST152. J Bacteriol 2008, 190(11):3962-3968.

51. Breurec S, Fall C, Pouillot R, Boisier P, Brisse S, Diene-Sarr F, Djibo S, Etienne J, Fonkoua MC, Perrier-Gros-Claude JD, Ramarokoto CE, Randrianirina F, Thiberge JM, Zriouil SB, Working Group on Staphylococcus aureus Infections, Garin B, Laurent F: Epidemiology of methicillin-susceptible Staphylococcus aureus lineages in five major African towns: high prevalence of Panton-Valentine leukocidin genes. Clin Microbiol Infect 2010, 17(4):633-639.

52. Schaumburg F, Ngoa AU, Kösters K, Köck R, Adegnika AA, Kremsner PG, Lell B, Peters G, Mellmann A, Becker K: Virulence and genotypes of Staphylococcus aureus from infection and carriage in Gabon. Clin Microbiol Infect 2011, 17(10):1507-1513.

doi:10.1186/1471-2334-12-286

Cite this article as: Shittu et al:: Characterization of methicillinsusceptible and -resistant staphylococci in the clinical setting: a multicentre study in Nigeria. BMC Infectious Diseases 2012 12:286.

\section{Submit your next manuscript to BioMed Central and take full advantage of:}

- Convenient online submission

- Thorough peer review

- No space constraints or color figure charges

- Immediate publication on acceptance

- Inclusion in PubMed, CAS, Scopus and Google Scholar

- Research which is freely available for redistribution 